To the Editors:

\title{
Hospital admission of children and psychological trauma
}

I happened to visit an operating theatre in one of the teaching hospitals in Sri Lanka recently and this was what I observed. A 3- or 4-year old child in a white gown was carried in by two people who were dressed in white clothes and wearing caps and masks. The child looked terrified and was crying. No sooner the child arrived, two ladies in light blue gowns, again with masks and caps, rushed to bring their machines close to the child. To add to all this the nurses were rushing around carrying surgical instruments, syringes and towels. The helpless child screamed in fear. The only response from the staff was a critical comment about the child's "inappropriate and unaceptable behaviour". Eventually after an injection the terrified child went into a deep sleep.

Such events are common in our hospitals. I recall another girl of about 8 years referred for psychiatric assessment. She had become very boisterous and was hitting the ward staff. On inquiry we found that she was rebelling against the ward staff because she was kept in the ward for several weeks for various investigations. It was the New Year period, and the girl was upset that she had to be in the hospital when her siblings and friends were celebrating.

Studies done in the west $(1,2)$ have demonstrated that when a child is admitted to hospital there is an initial period of protest where the child manifests acute distress, accompanied by crying and restlessness. Then there is a period of misery and apathy; the phase of despair. If the separation continues for a long period there may be a phase of detachment where the child may not be bothered about parental visits and may become more attached to the care givers. The process of reunion may give rise to further unsettled behaviour, with avoidance of parents, marked clinging, and angry outbursts. It has also been shown that the parents' anxiety can contribute to the child's distress. Futhermore, the cognitive and emotional developmental level of sick children can influence their symptoms (3). Intense psychological trauma can lead to post-traumatic stress disorder. The hospital staff often neglect this aspect in the care of children. Planned admissions, where both the child and parent are prepared, can reduce parental anxiety and the child's distress (4,5).

\section{References}

1. Bowlby J. Attachment and loss. Separation, anxiety and anger. v 2. London: Hogarth Press, 1973.

2. Rutter M. Separation experiences: a new look at an old topic. Journal of Paediatrics 1979; 95: 147-54.

3. Kaplan HI, Sadock BJ. Comprehensive textbook of psychiatry, v. 2.6th ed. Baltimore: Williams and Wilkins 1995: 2469.
4. Ferguson BF. Preparing young children for hospitalization. Paediatrics 1979; 64: 656-64.

5. Wolfer JA, Visintainer MA. Pre-hospital psychological preparation for tonsillectomy patients: effects on children's and patient's adjustment. Paediatrics 1979; 64: 646-55.

K A L A Kuruppuarachchi, Senior Lecturer in Phychiatry, Faculty of Medicine, University of Kelaniya, Ragama, Sri Lanka. 